Netiva Caftori

African Women and the Internet

\begin{abstract}
:
As the future of the Internet in Africa seems promising from an infrastructure point of view, the issue of the women of Africa should not be forgotten, in particular women who are already in academia who continue to struggle for equality despite their relative achievements.
\end{abstract}

Women all over the world face similar hurdles and conflicts related to their gender, such as tenure vs. biological clock and shrinking pipeline. However the glass ceiling in the West is made of iron in Africa. One cannot yet aspire to reach the top.

Luckily thanks to the Internet, women communicate with each other and African women as well are being heard. The Internet is serving them as a sound board and support in their struggles.

\title{
Agenda
}

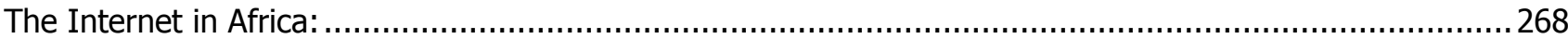

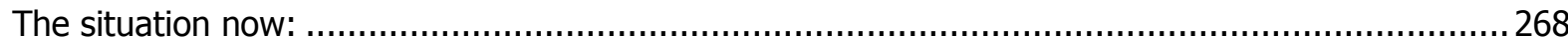

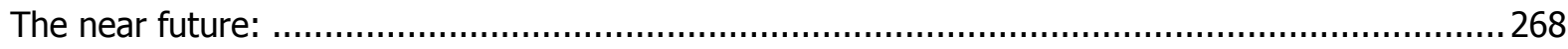

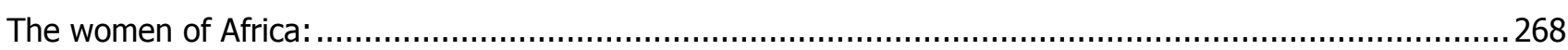

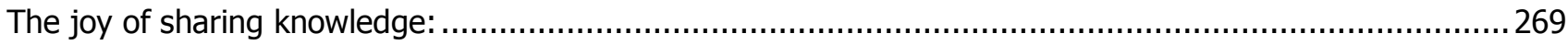

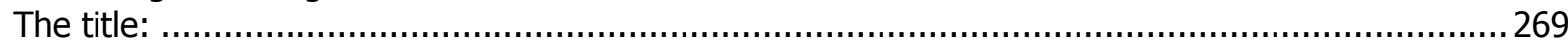

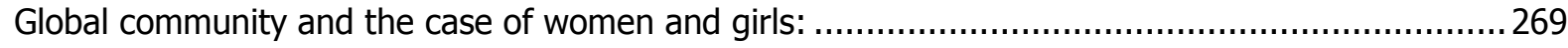

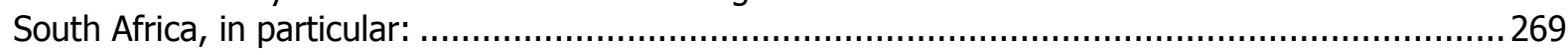

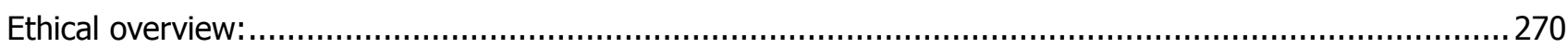

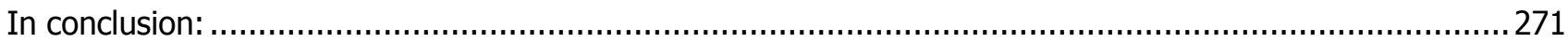

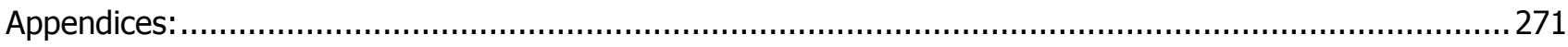

Author:

Prof. Dr. Netiva Caftori:

- Computer science department and Women studies program, Northeastern Illinois University, $5500 \mathrm{~N}$. St Louis avenue, Chicago, Illinois 60625

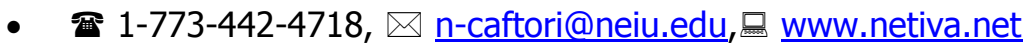

- Relevant publications:

- "Women in Computing", Oct 2004, University of Central Florida (UCF), Women Research Center

- "L'ethique en informatique », June 16, 2004, Cotonou, Benin

- "Ethical Reflections", paper delivered at EEI21, Oct. 2001, published by McFarland Press.

- "Computers and Major Ethical Problems of Society", presented with Alfred Bork at the University of Memphis at the EEI21 Conference (Ethics in Electronic Information in the 21st Century), 1998, published in Simulation journal, 1999.

- "Ethical Implications of Technology on Education", Pugwash conference, UCSD, 1999 


\section{The Internet in Africa:}

\section{The situation now:}

As the Internet continues to gain momentum throughout Africa, people in many countries are becoming more knowledgeable about connectivity, content development, training, and public policy issues.

Yet the numbers of users are still relatively small: 425,000 Internet users in Benin as of Sept. 2006, which is $5.7 \%$ of the population, and less than a million in all of Africa, which represents $3.6 \%$ of the total population according to International Telecommunications Union (ITU.) More world statistics can be seen at: http://www.internetworldstats.com/stats.htm.

The Internet Society (ISOC) continues its longstanding effort to promote the development of the Internet in Africa through its INET Africa Conference 4 May 2007 in Abuja, Nigeria. INET Africa is held in conjunction with the AfriNIC 6 and AfNOG 8 meetings.

\section{The near future:}

Efforts spent on the connectivity level are aimed at getting 50 African countries online with various speeds ranging from $64 \mathrm{k}$ or lower up to hundreds of $\mathrm{Mb} / \mathrm{sec}$ in some cases. The next phase includes the local training and human resource development of support staff in many communities in Africa. This represents much progress achieved in the direction of access.

Africa is now facing new challenges such as a shift from development of the infrastructure only to development of info-structure as well. Several hot issues are being explored, such as local languages, content update, intellectual property, and security. Regarding Internet governance and policy issues, Africa is shaping its efforts as well. The establishment of an African Network Information Center for the management of the IP addresses is under development.

Two other major topics of concern to Africa addressed in the 2007 ISOC conference are: Internet security, and detecting and deterring unwanted Internet traffic. Much work is to be done in this domain just as it is all over the world. Security may just be an elusive goal.

\section{The women of Africa:}

As the future seems promising from an infrastructure point of view, we should not forget the issue of the women of Africa, and in particular women who are already in academia who continue to struggle for equality despite their achievements.

Women all over the world face similar hurdles and conflicts related to their gender, such as tenure vs. biological clock. The glass ceiling in the West however is made of iron in Africa. One cannot even aspire to reach the top.

The number of women in computing, and in academia in general, is higher in the West than in Africa although it is steadily declining. In the West the problem is recognized and efforts are made to remedy. In Africa however the issue is not yet dealt with openly. The culture is so that a woman's place is with her family and her work should be within the family. In the West many women have broken this stereotype some time ago and are working outside the house to develop themselves and not just their families.

Luckily thanks to the internet, many women communicate with each other and African women as well are being heard. The internet is serving them as a sound board and support in their struggles.

This social tool may prove to be more revolutionary in Africa than in the West. It serves as a highway straight from someone's home even if there is only a dirt road outside of the physical house. An African woman may have to take a leap to use this highway, a more difficult task than for her sister in the west, but by doing so she can reach much farther than her neighbors who don't try.

From my own experience living a year in Benin, West Africa, in 2003-04, I know women there are proud and self confident. They have achieved relative equality when it comes to economical and financial independence. In many rural areas of the South they are partners with the men. They still have a long way to go from a social stand point. In academia also their numbers are few and need to increase so they can serve as role models for future generations.

Poverty in many African countries bound with old beliefs keep women at home and at work, far from school benches and lacking books and other educational resources. 
Let me expand further down on the current situation of university women in particular and how informatics can help stabilize their role in the African society.

\section{The joy of sharing knowledge:}

\section{The title:}

The title of the conference reminds me of a recurring theme between my husband and I, which I may argue, could be generalized to a theme between men and women. Women, who value socialization more readily than men, generally like to share information more willingly as well. Men, whose motive in life is most likely to climb up the ladder of success, is to retain information so that their rivals will not use it to advance themselves. Sounds familiar? This of course may be a Western way of life. However gender inequality in Africa should be one of our issues of concern too.

The Western world instead of sharing of its knowledge, which it does to some degree, inadvertently steals brain power from Africa. The rich and powerful in Africa send their children to study abroad. The talented get stipends and leave their native countries sometimes to never return. Of course many do return and bring a wealth of knowledge to help their countries out of poverty but many do not.

Therefore it is a comforting idea to participate in a conference that has as its title the sharing of knowledge to advance the good of all.

Sharing of knowledge implies trust; trust that the receiving party will acknowledge and appreciate the source and will in turn reciprocate so all parties involved will benefit in the long run; hence comes the joy. Many of us believe that this is the only way to advance science and culture throughout the world.

A rich country confident in its resources can begin by sharing and giving to the less fortunate.

When Africa recognizes its full potential, its brain resource, among others, it can start by keeping it there and using it with proper compensation to benefit all involved.

Industries can be developed producing chips and the like (using their hard working potential) and data centers including programming and system developing centers.
India, for example, has achieved such a status. Why not Africa with its French-speaking potential for example?

\section{Global community and the case of women and girls:}

We live in a global community. Neglecting one part of the community hurts us all in the long run.

In Africa universities remain male-dominated and male-structured. That can be particularly true in sub-Saharan Africa where 20 million girls are denied any education due to discrimination, poverty and conflict according to a 2005 Save the Children report.

In Benin, West Africa I witnessed gender discrimination. In the graduate institute where I taught (IMSP) there were very few women (less than 10\%) who came usually from rich families or foreign countries. They themselves were not aware of direct discrimination except sometimes from their own families who wanted them to marry instead of study. However I realized later on by teaching a Women-in-Computing course in the US (where women in computer science represent $20-30 \%$ of the general student population) that no one was aware of discrimination until eyes were opened to it. In a survey I conducted just this past semester in my class none of my students felt there was any such discrimination in our department or anywhere. It's only in mid term or at the end of the semester after much reading and discussions into the topic did the students start seeing the truth.

It seems similarly will happen in Africa. Right now many women deny there is discrimination. Their eyes are just not open to see it yet. It will not take long I believe as the proliferation of the Internet and western influence will bring with them greater awareness and a desire for more.

\section{South Africa, in particular:}

Post-apartheid South Africa is widely agreed to be a Mecca. But even there, senior women-faculty are scarce. At Johannesburg's University of the Witwatersrand, for instance, women account for only 19 percent of associate professors and 17 percent of full professors in recent years, according to Dr. Hilary Geber, a professor there. In South Africa, female faculty of color are particularly rare. At the University of Cape Town, women account for 35 percent of the school's overall academic staff of 779 . 
But only 59--or 8 percent--are women of color, according to Nazeema Mohammed, who oversees the school's transformation from the apartheid system. Representation at universities is just part of the problem. "The insufficient support for the production, dissemination and use of African feminist knowledge and theory, in all fields, is surprising." Groups such as AGI (the African Gender Institute) are using technology as a major tool to overcome those hurdles.

Online connections to other female thinkers and advocates help make up for the camaraderie that's often lacking for women at African universities; it's a loneliness that may lead many to leave the continent to pursue graduate-level studies. "The Internet and technology play a big role in breaking the isolation," says Dr. Elaine Salo, a senior lecturer at the African Gender Institute. "We are doing work here that will result in a generation of scholars who will say: 'we can do work here that is relevant to our society.'

The institute was founded in 1996, two years after South Africa's transition from apartheid to democracy, to expose African researchers and intellectuals to the importance of gender equity and to support those engaged in that process.

Housed in offices at the University of Cape Town, AGI offers undergraduate and graduate academic programs in gender and women's studies. Three core teaching faculty also raise up to $\$ 1$ million a year from international foundations to offer programs for African scholars committed to gender equity.

Female academics in Africa also exchange ideas and information through a number of other Web sites such as:

FEMNET in Kenya,

Zimbabwe's Women's Resource Center and Network,

Uganda's African Women's Economic Policy Network and

Cameroon's Association for Support to Women entrepreneurs.

To ensure as many readers as possible, Feminist Africa http://www.feministafrica.org/ is published both as a traditional 150-page academic journal, as well as on a free Web site.

http://www.gwsafrica.org/
GWS Africa is a project of the AGI, sponsored by the Ford Foundation

Tamale has become the first female dean of Makerere University's Faculty of Law in 2004 and, earlier this year; she launched a research project on Gender, Law and Sexuality, which she hopes will someday become

fully fledged research center.

The origin of the newly established Institute for Women's and Gender Studies of Pretoria University (the fourth of its kind in South Africa), is not dissimilar to the origin of women's and gender studies elsewhere in Africa. Whereas the women's movement had played a fundamental role in the establishment of women's and gender studies in the West, women's movements in Africa have not played a similar role in the institutionalizing of women's and gender studies in Africa. On the contrary, the main forces behind the institutionalizing of women's and gender studies in Africa have been Western financial support, conceptual apparatuses and theoretical models. (From the preface by the director of WGS of Pretoria U)

Even Oprah Winfrey has opened a school for girls in the small town of Henley-on-Klip, south of Johannesburg, S. Africa. This is another example of a Western concept which may impact the local culture.

\section{Ethical overview:}

We need to realize that cyber ethics are different than the ethics we had to deal with since biblical times.

What makes ethics online a unique moral issue according to Deborah Johnson can be summarized in the following three points:

- The scope of the Internet is global and interactive.

- The Internet enables users to interact with anonymity.

- Internet technology makes the reproducibility of information possible in ways not possible before.

The above features make behavior on-line morally different than off-line. In a country where not too many people use the Internet or one gender uses it substantially more, these differences create a wider digital gap that one should avoid. 


\section{In conclusion:}

In the industrialized world computers are changing everything: from education to health, from voting to making friends or making war.

Many countries fully participate in cyberspace and make use of opportunities offered by global networks.

We are living a technological and informational revolution.

It is important for policy makers, leaders, teachers, computer professionals and all social thinkers to get involved in the social and ethical impacts of this communication technology. Women in particular can be invaluable as they are more naturally communicative.

Not involving women in this new technological world is immoral ${ }^{1}$. A society that doesn't use its entire citizenry is losing on attaining its full potential. It's only through diversity that a society can reach the full rainbow of its colors.

\section{Appendices:}

\section{Telecenters:}

There has been a proliferation of telecenters providing access to information and communication technologies (ICTs), initiated by governments, the private sector, international donors, and community organizations. Telecenters address the lack of ICTs throughout Africa and assist in providing universal access, to both telephony and other forms of communication.

Senegal is the African country with the largest number of telecenters: more than 9,000.

Other major centers were established in Mali, Uganda, Mozambique, and South Africa by foreign organizations but had a hard time once on their own.
Nakaseke Multipurpose Community Telecenter (MCT) in Uganda is a more realistic and successful center.

Purely market-driven initiatives are likely to increase the digital divide within Africa. There doesn't exist yet a model for sustaining community access centers that can provide access for the majority.

Rarely should foreign funding be 100 percent (all the economic lessons of entrepreneurship should be used)

The greatest potential to bring access to ICTs throughout Africa is to support smaller businesses and community organizations that develop new services themselves. Through telephony, they can offer fax, or secretarial, or computer, or even Internet services.

"The individual who sublets his or her phone line or sets up a phone shop or telecenter does more to close the development gap than the great corporations and businesses of the world." By ITU secretary-general Pekka Tarjanne.

Second appendix at the end.

\section{References:}

Irene Albert: Des femmes; une terre. Une nouvelle dynamique sociale du Benin; L'Harmattan, 1993.

Peter Benjamin: African Experience with Telecenters;

http://wWw.isoc.org/oti/articles/1100/benjamin. $\underline{\text { html }}$

Laurie Garrett: The betrayal of trust: The Collapse of Global Public Health

Marita Golden: Don't play in the sun: One Woman's Journey Through the Color Complex

Tarek Kamel and Terry Weigler: African Chapters and Their Role in Internet Development in African Countries, http://www.isoc.org/oti/articles/0401/kamel.htm I

Gretchen L. Wilson, WeNews correspondent: African Female Scholars Share Virtual Lifeline;

http://www.isoc.org/isoc/conferences/inet/06/maurit ius.shtml

http://www.internetworldstats.com/stats1.htm

http://www.brad.ac.uk/research/ijas/links.htm

http://www.africa.upenn.edu/Home Page/mcgee.ht ml, 2004

${ }^{1}$ Deborah Johnson and Keith Miller: is diversity in computing a moral matter? 
http://www.afrinic.net//

http://www. computers4africa.org/

Computers to Africa scheme criticized:

http://news.bbc.co.uk/2/hi/africa/2989567.stm
Internet Society (ISOC) annual report, 2005: http://www. isoc.org/isoc/reports/ar2005/

Internet Society Programs Helping Africans Develop Internet in Africa: http://www.isoc.org/isoc/media/releases/07050 3pr.shtm/

\section{Appendix b:}

\begin{tabular}{|l|l|l|l|l|l|l|}
\hline $\begin{array}{l}\text { Population } \\
\text { (2006 Est. ) }\end{array}$ & $\begin{array}{l}\text { Pop. } \\
\text { in World }\end{array}$ & $\begin{array}{l}\text { Internet Users, } \\
\text { Latest Data }\end{array}$ & $\begin{array}{l}\text { Penetration } \\
\text { \% Population) }\end{array}$ & $\begin{array}{l}\% \text { Users } \\
\text { in World }\end{array}$ & $\begin{array}{l}\text { Use Growth } \\
(2000- \\
2006)\end{array}$ & \\
\hline Total for Africa & $915,210,928$ & $14.1 \%$ & $32,765,700$ & $3.6 \%$ & $3.0 \%$ & $625.8 \%$ \\
\hline Rest of World & $5,584,486,132$ & $85.9 \%$ & $1,053,485,203$ & $18.9 \%$ & $97.0 \%$ & $195.5 \%$ \\
\hline WORLD TOTAL & $6,499,697,060$ & $100.0 \%$ & $1,086,250,903$ & $16.7 \%$ & $100.0 \%$ & $200.9 \%$ \\
\hline
\end{tabular}

